\title{
Study of Topology Optimized Hammerhead Pier Beam Made with Novel Preplaced Aggregate Fibrous Concrete
}

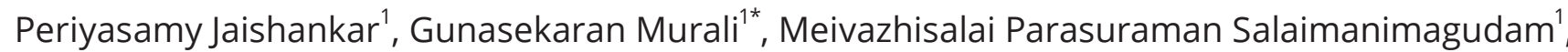 \\ Yahya Hussein Mugahed Amran ${ }^{2,3}$, Roman Fediuk ${ }^{4}$, Kothandapani Karthikeyan ${ }^{5}$ \\ ${ }^{1}$ School of Civil Engineering, SASTRA Deemed University, Thanjavur, 613401, India \\ ${ }^{2}$ Department of Civil Engineering, College of Engineering, Prince Sattam Bin Abdulaziz University, 11942 Alkharj, Saudi Arabia \\ ${ }^{3}$ Department of Civil Engineering, Faculty of Engineering and IT, Amran University, 9677, Quhal, Amran, Yemen \\ ${ }^{4}$ School of Engineering, Far Eastern Federal University, Vladivostok, 690950, Russia \\ ${ }^{5}$ SMBS, VIT Deemed University, Chennai, 600127, India \\ * Corresponding author, e-mail: murali@civil.sastra.edu
}

Received: 22 July 2020, Accepted: 16 October 2020, Published online: 09 November 2020

\begin{abstract}
This study aims to study topology Optimized Hammerhead Pier Beam (TOHPB) designed with a density-based technique. TOHPB is made with Preplaced Aggregate Fibrous Concrete (PAFC), which comprises two main preparation processes. First, the fibers and coarse aggregates filled into empty formwork to develop a skeletal system. Second, voids in the skeletal system are filled with cement grout; hence a type of PAFC was obtained. Besides, alleviating the self-weight of the concrete beam is a top priority of design engineering without compromising its strength and durability. The effect of topology optimization in association with the safety of factors and elastic design case is considered in this study. Explicitly, (i) compliance is scaled down to a minimum under a perimeter on the utilized material (ii) the principle Drucker-Prager is employed to impose the stress limitations even though utilization of material is minimized. The problem is designed with imposed stress limitation and generates keys that involve an essential part of post-processing before fabrication. In total, ten TOHPB were prepared with and without the combined shape of crimped-hooked end steel fiber. Two different types of fiber reinforcement schemes were used; first, the fibers were reinforced to full beam cross-section; then, the fibers were reinforced to the top half of the beam cross-section. Results revealed that the TOHPB beam reinforced full cross-section exhibited better ultimate load performance than that of the beam with half reinforced cross-section.
\end{abstract}

Keywords

topology optimization, fibers, beam, grout, displacement

\section{Introduction}

A computational method for optimizing structures is a significant contribution to enhancing the design of products in diverse sectors. The aerospace and automotive industrial sectors, for instance, make widespread utilization of such technology for weight reduction and enhancing stiffness, among other objectives [1]. Most notably, topology optimization is evolving as a tool for a generic design that makes it possible to use in a broad spectrum of technological fields, spanning from nanophotonic up to aircraft [2]. The optimum design had little influence on conventional bridge engineering as experienced in the construction sector. Because of the design of reinforced concrete at a specific case, optimization is unusually difficult due to complications in uniting tools of numerical optimization tools with precise constitutive models. This moves in the direction of the sustainable design of structures open a gate of significant scope for using optimization method in structural design. Production of cement is accountable for approximately $5 \%$ emissions of carbon dioxide yearly [3]. In practice, every 1 tonne of cement production emitted 0.9 tonne of carbon dioxide [4]. This triggers a search for innovative design methods that enable weight reduction of the concrete structure without compromising the desired load-bearing capacity. This paper aims to propose a topology optimization of structural components for bridge applications. An increased focus within the world architecture community has been increased recently due to the creativity of aesthetic structural form through topology 
optimization [5]. Till today, the optimized structural member is examined through the numerical simulation, and its experimental testing was not explored by many researchers.

In recent years, several research types have been conducted on algorithm-based topology optimization for reinforced concrete elements. The primary research aims at Strut-and-Tie Models for designing, and placement of reinforcements at the optimum position and effective directions. The suggested course of action simplified the concrete as anisotropic and elastic material utilized in the topology optimization of the truss [6], or density-based methods [7]. The topology optimization of strut-and-tie models with the different modules in the two reinforced concrete phases was later recommended [8]. The continuum outline for the design of the conceptual reinforcement phase in reinforced concrete phases has elastoplastic performances, and Bogomolny and Amir [9] proposed it. A new technique for column design for orthogonal structures was developed by Shaw et al. [10]. Briseghella et al. [11] emphasized that the tension zones inevitable stresses could be taken care of by material-removing from the shell regions in which bending occurs. This produces more voids in concrete, which satisfy the conditions of topology optimization.

The topology optimization design layout, fiber orientation, and its distribution in fiber reinforced concrete have been proposed by earlier studies [12]. Further comprising the design of the reinforcing phase alone, algorithms based topology optimization has been offered for design of both phases to enhance the destruction strength of lightweight components [13]. Lately, an algorithmic topology optimization for the design of lightweight post-tensioned reinforced concrete was suggested by Amir and Shakour [14]. Søndergaard and Dombernowsky [15] investigated a reinforced concrete frame designed by the assumption of isotropic behavior of the material in an initial phase of design. Its results were post-processed by the addition of reinforcement to counter tensile forces in the frame. The modern deficiency of experimental corroborations makes a major disadvantage for new improvements and the practice of topology optimization in reinforced concrete design. As reinforced concrete is a complex composite, this line of work emphasizes precisely designing for the concrete phase, an indispensable stage in truly allowing the freeform design of both reinforced concrete phases.

Concrete is one of the building materials used frequently in constructions, such as road projects, infrastructure, and other various applications. Due to the problems faced by traditional concrete, such as casting difficulty and high costs of concreting in some places and applications. Some problems can also guide us in conventional concrete, such as segregation in its component, honeycomb, drying shrinkage, and other problems that affect the quality of the concrete produced. Another type of unconventional concrete that has been developed in engineering applications to overcome traditional concrete uses challenges and limitations. Such different type of concrete has been prepared in a way that is quite distinct from traditional concrete in mixing, handling, and casting. Preplaced Aggregate Concrete (PAC) is a new kind of concrete comprising two main processes of preparation; first, the fibers and coarse aggregates filled into empty formwork to develop a skeletal system, second, voids in the skeletal system are filled with cement grout [16]. This permits more coarse aggregate filling the empty formworks and interlocking there between, which is an exceptional vis-à-vis conventional concrete casting technique. This unique casting technique of PAC holds a high coarse aggregate content that alters the behavior of concrete and its properties. For instance, the interlocked coarse aggregates upturn the points of contact of these particles [17], which causes improved stress distribution during loading and influencing the mechanical properties of concrete [17]. The mechanism of resisting external loads by PAC is differing from that of conventional concrete [17]. On account of close contact between the coarse aggregate skeletons, the transformation of stress in PAC happens first in coarse aggregate skeletons after that in the grout as displayed in Fig. 1 (a), (b) and (c) [17].

Currently, a dearth of experimental validations causes a major impediment for future evolution and utilization of topology optimization in structural design. To fulfil this

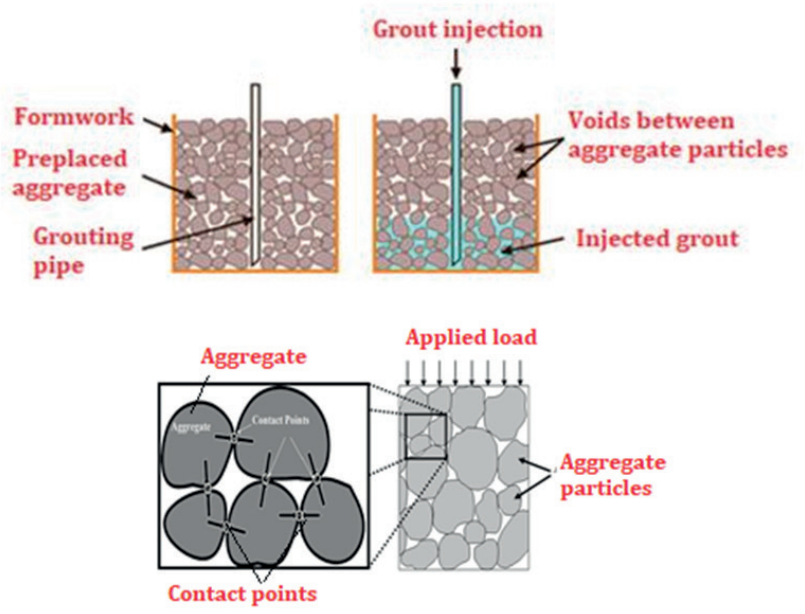

Fig. 1 (a) Coarse aggregate placement (b) pumping process of grout injection through pipe network and (c)stress transfer mechanism in TSC [17] 
knowledge gap, the research goal is described herein to investigate the static response of topology optimized hammer pier beam. All designed TOHPB made with PAFC casting technique comprising two different dosages of steel fibers ( $2 \%$ and $4 \%$ ) with two schemes of fiber reinforcement (full cross-section and tension zone only).

\section{Topology optimization}

The structural optimization is the method of achieving the most optimal structural element without affecting its structural efficiency. These techniques are utilized to determine the optimal boundary of the material within the design domain, meanwhile minimizing the compliance of a structure. Mesh refinement plays a crucial role in topology optimization [18]. Structural element analysis is utilized for minimizing the error during the determining process of compliance, stress, and strain. This can be used to have an accurate estimation of the material boundary in a design domain and also increases the post-processing. The post-processing method is used to make geometry transformation from topology to shape optimization. The density-based method is used in topology optimization, and it can be executed by the homogenization method [19] and the Solid Isotropic Material Penalization (SIMP) method. In this study, the SIMP method is used to execute the topology optimization. This method defines the density of each element in a design domain and gives a result of a binary variable between 0 to 1 , while zero represents the voids, and one denotes the solid. The material stiffness is linked using the power law

$$
E=\rho^{p} \times E_{o},
$$

where $E$ is the stiffness, $\rho$ is the density of concrete, $p$ is the coefficient of penalization and $E_{o}$ is the Young's modulus of isotropic material. Eq. (1) penalizing the intermediate densities and relatively low stiffness, as shown in Fig. 2.

The optimization results show more intermediate densities. Guest used the Heaviside functions to overcome the blurred boundaries by more iterations. Several suggestions were reported based on methods in topology optimization [20]. In general, a design domain with support conditions and applied loads should be defined by a structural engineer. The challenging design is expressed as a formalized problem in optimization, and most scrupulously broken out with the help of arithmetical programming. The approach of solid isotropic material penalization (SIMP) was used in this study. The SIMP approach

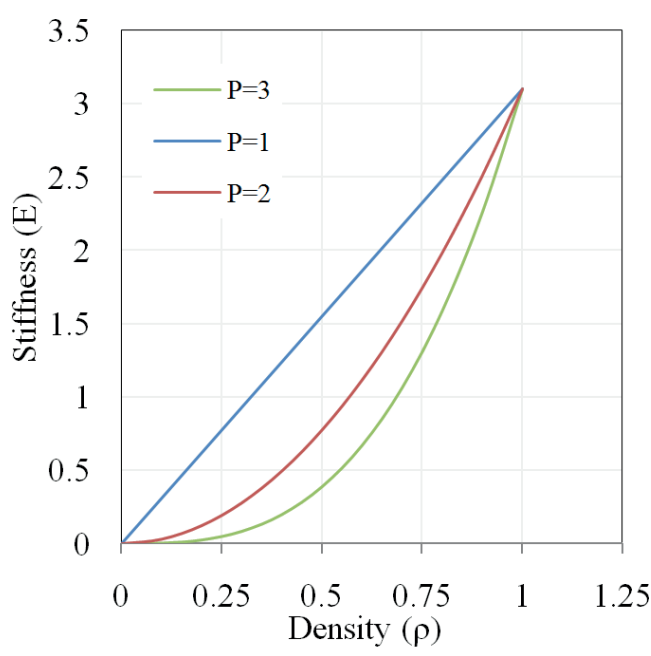

Fig. 2 Values of intermediate density

rarely distinct as a density method that works with fixed finite element discretization, each finite element is associated with a density function $\mathrm{Xe}$. The design domain target is to determine a $0-1$ element densities distribution that optimizes a defined objective while satisfying the equilibrium of structure and number of given constraints. However, the use of gradient-based optimizers, the constraints of $0-1$ binary is made easy and densities at intermediate level $(0 \leq X e \leq 1)$ are permitted as the design evolutions. Equally, the densities at the intermediate level are castigated to drive them to use incompetent material in the significance of which the optimizer is concentrating from an initiative tarnished postulation with a view towards a separate structural input.

The topology optimization framework involves additional benefits as compared with the conventional approach finite element analysis. This replies to the optimization mechanism, which presents optimal constituent topology according to the given design parameters and constraints. The achievement of processing for the proposed frame is illustrated in Fig. 3. Standard pre-processing of the Fusion 360 mass information organizer includes precise optimization objectives, constraints, and variables. Supplementary pre-processing of optimization precise information such as adjacency, distances, manufacturing constraint dependence, and preliminary volume fraction are considered during the analysis. In the design procedure of topological optimization, iteration initiated with manipulative stiffness followed by mass matrixes, and all succeeding are scaled. The optimization mechanism decides new design parameters (scaled stiffness and mass) and is manipulated continuously until the stopping criteria are fulfilled. 


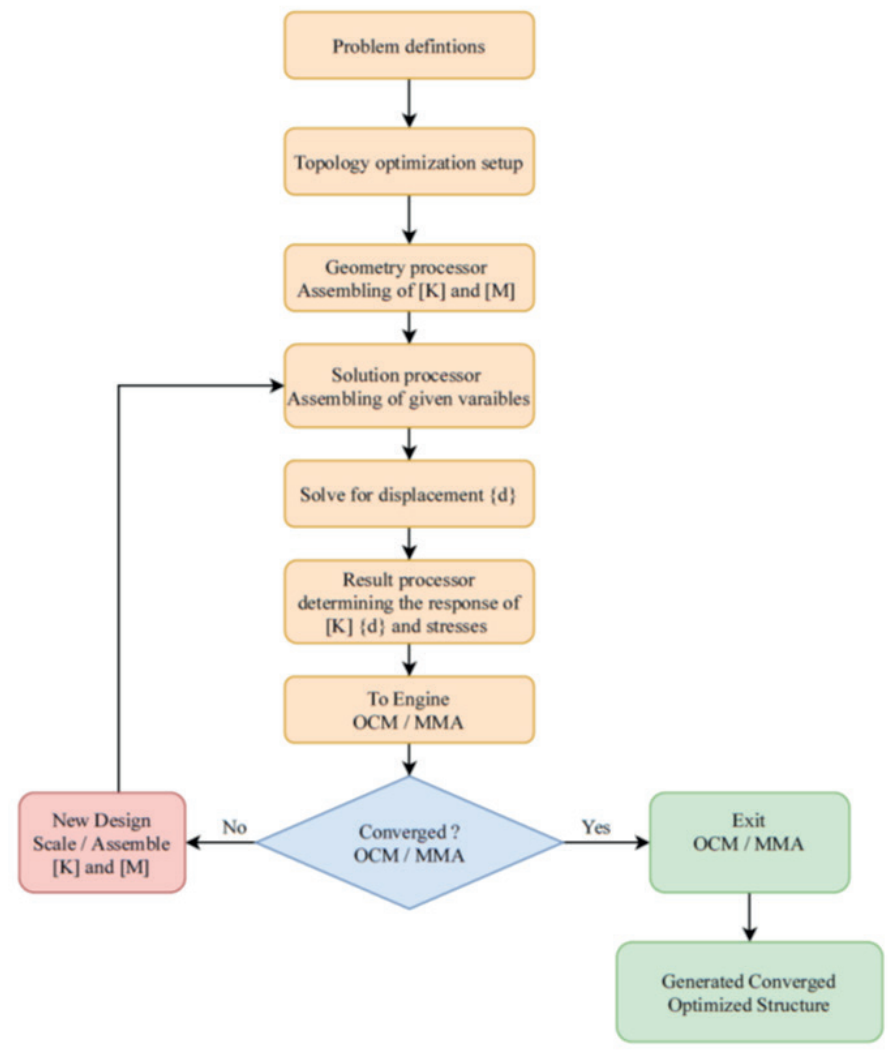

Fig. 3 Topology Optimization framework

\subsection{Optimality Criteria Method (OCM)}

Optimality Criteria Method is used for massive structural components with several structural constraints and design variables [21]. The OCM gives the ultimate optimal design for a short duration and huge structures under deformation and frequency constraints [22]. This adequate for structures with fewer numbers of design variables, even its works prefect in the occurrence of stress constraints [23]. OCM can be enormously utilized when stress requirements stressed the design [24]. The new variety of optimality criteria approach is projected by Lógó et al. [25]. OCM uses to accumulate the standard basic data from the earlier prominence is not involved. Hence its works preferably give enormous exhibitions in any occurrence, even for subordinate systems ability. OCM functions commendable with the solitary and numerous constraints, which are predominantly used with compliance objectives and volume fraction constrains [26].

\subsection{Moving Method Asymptotes (MMA)}

The method for moving asymptotes can effortlessly handle the several constraints, canvas data not accepted to stock up, and it necessary a smaller amount of space store information. The inmost limitation can be controlled by several engineers that need to tune these parameters for rapid combination and reliability. A variety of parameters can be functional inside a single model; Amir and Shakour [14] projected the topology optimization for prestressed concrete beams. This method is generally logical for structural topology optimization cases, and it can deal with any optimization problem. The MMA is the handiest optimization technique for any objective function and any number of constraints equations. Also, it reaches the optimum resolution with the least amount of run time. Utilizing the process of moving asymptotes makes it effortless to organize the convergence, stability, and speed of the optimization progression. It is significant noting that elevate the number of elements, the choice of asymptotes supposed to be enhanced to save much time [27].

\subsection{Post-processing}

The post-processing is having two-step, namely geometry extraction, and shape optimization, according to Rodrigues and Fernandes [28]. The schematic flow of topology optimization is illustrated in Fig. 4.

The most important reason for the presence of geometry extraction is the usage of varying geometric descriptions between the topology optimization and shape optimization. 


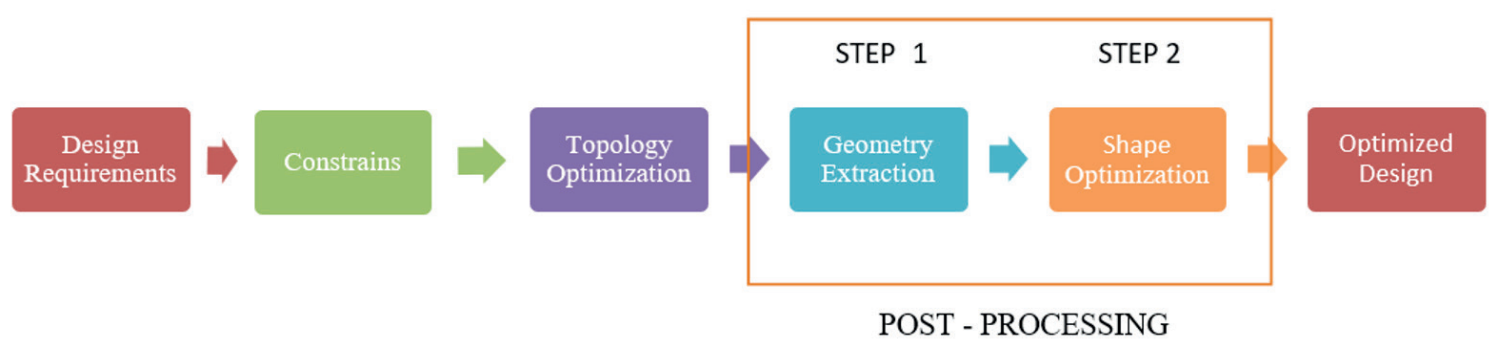

Fig. 4 Schematic flow of topology optimization

For example, the geometry of topology optimization from finite element analysis, but the shape optimization, is from splines [29]. The post-processing is carried because of the manufacturing constraints, which affects the efficiency of an optimized structure. Topology optimization is carried out over a hammerhead pier beam [30], and the effects of post-processing are reduced as a result of used 3D output from the topology optimization. At the same time, other researchers were used 2D outputs.

In this research, the $3 \mathrm{D}$ hammerhead pier beam is used in the design field, as illustrated in Fig. 5. Because of the loading, and size limitations of the used testing device, the domain length, depth, and thickness are defined as $\mathrm{L}=910 \mathrm{~mm}, \mathrm{H}=230 \mathrm{~mm}$ and $\mathrm{T}=76 \mathrm{~mm}$, respectively. The load $\mathrm{P}=2.2 \mathrm{kN}$ applied at the top surface of the beam at four different points, and constraints are positioned at the bottom center of the beam with the ratio of $L / 6$. The beam discretized with adaptive meshes. The non-fibrous and fibrous concrete hammerhead pier beam is presumed to behave isotropic and linearly elastic in all design situations. For the assumption of isotropic to be some extent strong for the pilot research, a scale prerequisite with the smallest length on the topological structures is imposed. Fig. 6(a) illustrates the obtained results from the topology optimization using Autodesk Fusion 360. The algorithm-based topology optimized design by the Jewett and Carstensen [31] is illustrated in Fig. 6(b). The four-bridge girder was considered, and it is resting on the four different top surfaces of the hammerhead pier

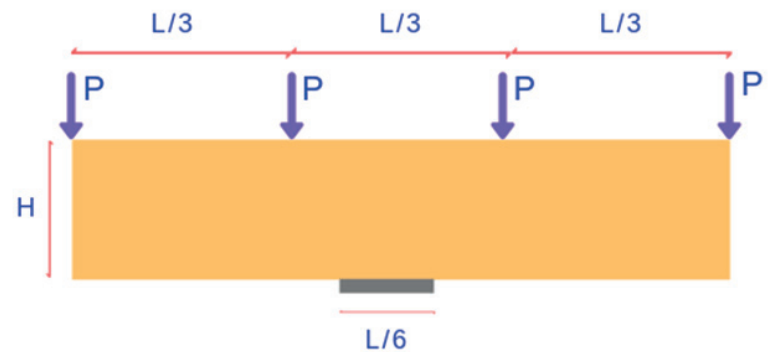

Fig 5 Field of design with boundary constraints and prescribed loads beam. Hence, the load was applied at four different points. Since the tested beams were prototype and a small load of $2.2 \mathrm{kN}$ was applied. The applied load was taken from the literature [31] to check the topology optimization's accuracy in this study.

\section{Experimental programme}

\subsection{Base materials}

Portland Pozzolana Cement was used as cementitious materials in conformity with IS:1489-1 [32], supplied by Dalmia Cement. The nominal maximum size of $4.75 \mathrm{~mm}$ river sand available in Thanjavur was utilized as fine aggregate with the fineness modulus of 2.6, the specific gravity of 3.14 , and a density of $2650 \mathrm{~kg} / \mathrm{m}^{3}$ in accordance with IS:383-2016 [33]. Coarse aggregates of well-graded with particle size ranged from 10 to $12.5 \mathrm{~mm}$ is picked into the account of the passing ability of cementitious grout and high inherent strength based on the trial test. The coarse aggregate had a specific gravity of 2.69 and water of $0.56 \%$. To meet the efflux time of grout, a Tech mix 640 commercial high range water reducing admixture was utilized to develop flowable cementitious grout. The water-reducing admixture dosage was varied from
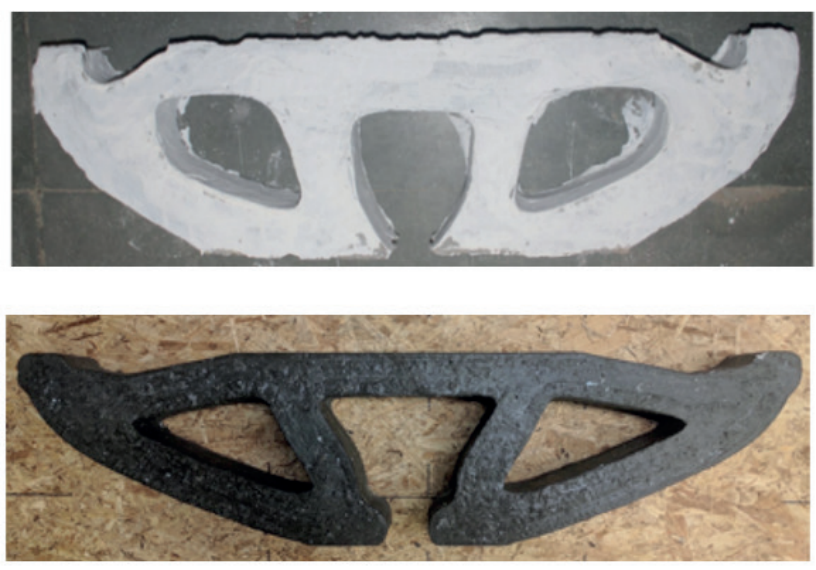

Fig. 6 Minimum compliance of beam (a) obtained from topology optimization (b) constructed optimized beam by Jewett, and Carstensen [31] 
$0.3 \%$ to $0.5 \%$ of the cement weight. New hybrid crimpedhooked end steel fibers manufactured by Purushottam steel wool industries in Nagpur, India were utilized in this study. The appearance of steel fibers utilized in this investigation as shown in Fig. 7 and its properties are demonstrated in Table 1.

\subsection{Mix composition}

In this study, five different TOHPB were prepared. Optimized (water/binder) $w / b$ and (sand/binder) $s / b$ ratio of 0.42 and 1.0 respectively were used to meet the efflux time and prevent honeycombing. To produce flowable cementitious grout in the aggregate and fiber skeleton, a Tech mix 640 commercial high-range water-reducing admixture was used. To achieve optimized $W / B$ and $S / B$ ratio, a series of trial tests were conducted to meet the efflux time of $35-40 \pm 2 \mathrm{~s}$ in agreement with ASTM C939-10 [34]. The dosage of the water reducing admixture is usually limited to $1 \%$ by weight of cement [35]. In this study, admixture dosages of $0.3 \%$ and $0.5 \%$ were used to produce non-fibrous and fibrous concrete, respectively. The first TOHPB is made with non-fibrous concrete is considered as the reference beam, and it is designated as NB-0. The second and third beams were reinforced with 2 and $4 \%$ dosage of fibers to entirely reinforced

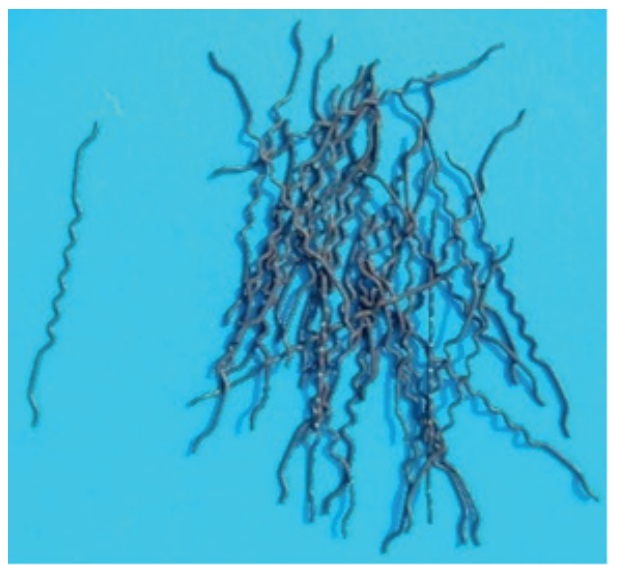

Fig. 7 Geometric shape of steel fibers

cross-section of beam and it was designated as FB-2 and FB-4 respectively. Fourth and fifth beams were reinforced with 2 and $4 \%$ dosage of fibers to the top half of the beam and were designated as FB-2-T and FB-4-T, respectively. The mix combinations and fiber dosages and reinforcement schemes used in the current study are provided in Table 2. Fig. 8 illustrated a reinforcement scheme and fiber dosage used in TOHPB for better understanding.

\subsection{Process of TOHPB preparation}

Initially, a steel framework of $910 \times 230 \times 76 \mathrm{~mm}$ was prepared. A topology optimized shape wooden solid blocks were cut from the $\mathrm{CNC}$ hotwire cutter was inserted into the steel framework to get the desired shape of TOHPB. Before casting, the pre-soaking of aggregates was done to put the coarse aggregates in a saturated surface dry condition to prevent the excessive absorption of water and, consequently, reducing the ultimate water/binder ratio of the grout. Fig. 9 demonstrates the fabrication technique of the PAFC beam, including the following subsequent actions. Firstly, the formation of the natural skeleton which involved placing fibers and coarse aggregate in the empty formwork

Table 1 Steel fiber properties

\begin{tabular}{lccc}
\hline Fiber type & $\begin{array}{c}\text { Length } \\
(\mathrm{mm})\end{array}$ & $\begin{array}{c}\text { Diameter } \\
(\mathrm{mm})\end{array}$ & $\begin{array}{c}\text { Tensile strength } \\
(\mathrm{MPa})\end{array}$ \\
\hline Crimped-hooked end fiber & 50 & 1 & 1150 \\
\hline
\end{tabular}

Table 2 Mix composition

\begin{tabular}{lcccccc}
\multicolumn{7}{c}{ Table 2 Mix composition } \\
\hline Mix id & $\begin{array}{c}\text { W/B } \\
\text { ratio }\end{array}$ & $\begin{array}{c}\text { S/B } \\
\text { ratio }\end{array}$ & $\begin{array}{c}\text { Efflux } \\
\text { time } \\
(\mathrm{Sec})\end{array}$ & $\begin{array}{c}\text { Fension } \\
\text { zone }\end{array}$ & $\begin{array}{c}\text { Compression } \\
\text { zone }\end{array}$ & $\begin{array}{c}\text { SP } \\
(\%)\end{array}$ \\
\hline PC & 0.42 & 1.0 & 36 & 0 & 0 & 0.3 \\
NB-0 & & & 36 & 0 & 0 & \\
FB-2 & & & 39 & 2 & 2 & 0.5 \\
FB-4 & & & 39 & 4 & 4 & \\
FB-2-T & & 39 & 2 & 0 & \\
FB-4-T & & 39 & 4 & 0 & \\
\hline
\end{tabular}

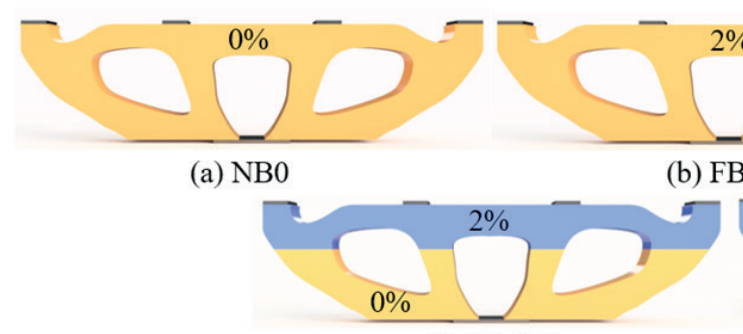

(d) FB-2-T (b) FB-2

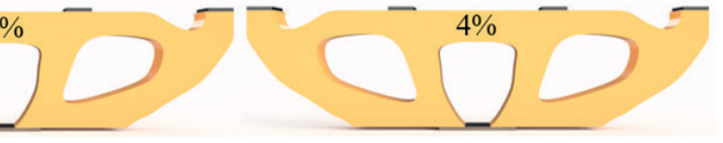

(c) FB-4

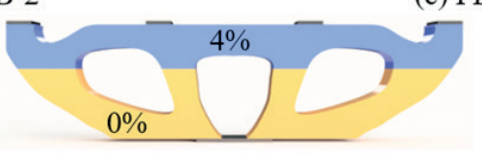

(e) FB-4-T

Fig. 8 Layout of fiber dosage in HHPB 


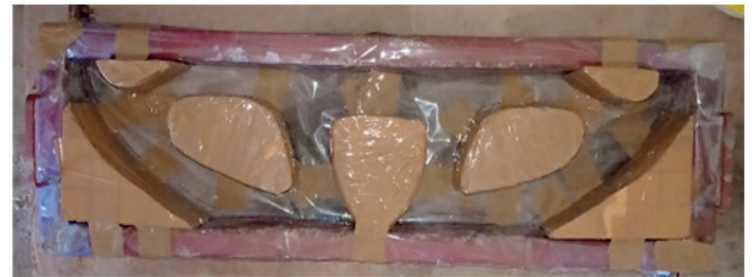

(a)

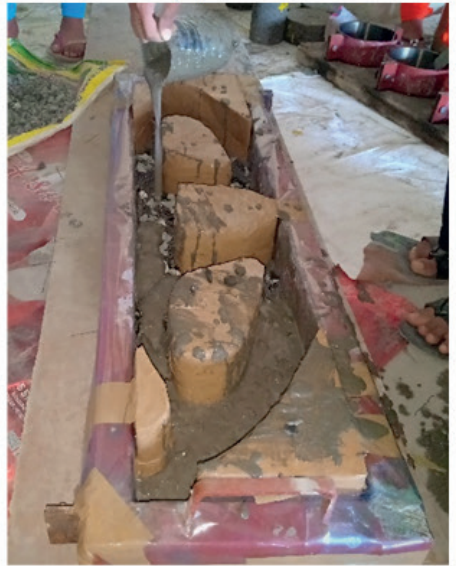

(c)

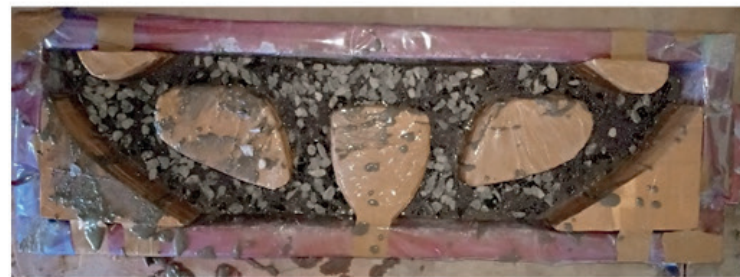

(b)

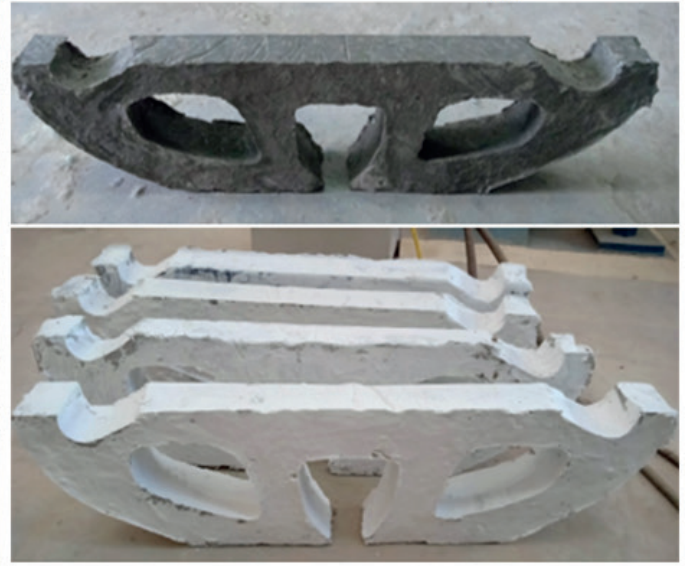

(d)

Fig. 9 Fabrication technique of PAFC(a) empty moulding framework (b) moulding framework filled with fibers and aggregates (c) grout pouring and (d) finished beams

up to $25 \mathrm{~mm}$ in a special way, is displayed in Fig. 9(a) and (b). Secondly, interstitial voids in the formed skeleton were filled by grout injecting by the method of gravity as displayed in Fig. 9(c). The same procedure is adopted to complete the remaining two layers (25 and $26 \mathrm{~mm}$ ). The finished surface of the grout injected beams is shown in Fig. 9(d). To assure a high compactness standard and prevent honeycombing, light vibration was applied. Additionally, three types of specimens; $100 \mathrm{~mm}$ cubes, $100 \mathrm{~mm}$ diameter and $200 \mathrm{~mm}$ height cylinders, and $100 \times 100 \times 500 \mathrm{~mm}$ prisms were prepared to evaluate the compression, split tensile and flexural strength respectively.

\subsection{Test setup}

The compression and flexural strength tests were conducted in conformity with IS 516 [36] and split tensile strength were conducted according to IS 5816 [37] recommendations. The average results of three specimens were used for discussion. The experimental testing was conducted to observed the load-deflection curve using the deflection control loading frame. A test rig of steel tubes with square cross-section offered the deflection to the four loading points by stringer the right balance of a steel tube at its focal point on steel rods. In this experimental design, the support conditions were provided by introducing the rectangular steel plate, which was bonded at the outermost concrete surface using high strength epoxy. To observe deflection at four loading points, a four Linear Variable Differential Transformer (LVDT) was used; the compliance beam with the LVDT test fixture is displayed in Fig. 10. However, the design in this research was restricted to beams inelastic range, and all beams were loaded till failure to observe nonlinear behavior.

\section{Discussion of results}

\subsection{Mechanical properties of PAFC}

Fig. 11(a) illustrates the compressive strength (CS) results for the PAFC specimens by adding 2 and $4 \%$ steel fibers at 28 days. Findings revealed that the compressive strength

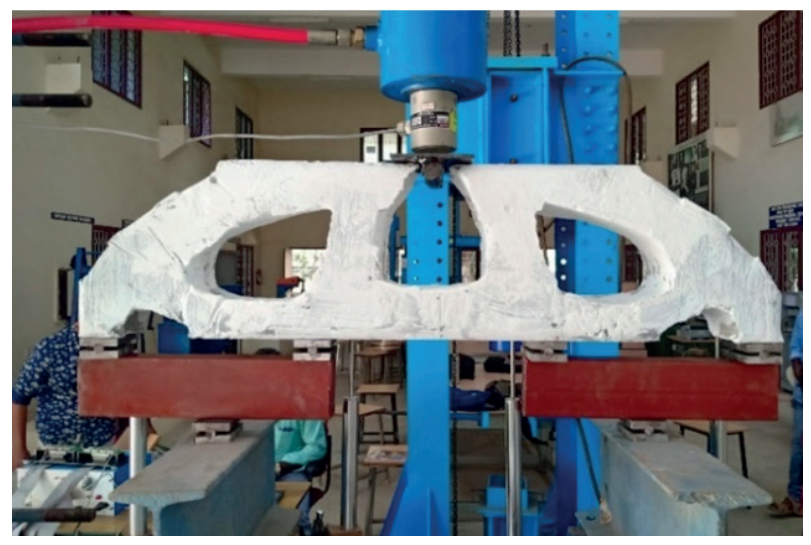

Fig. 10 Experimental test setup 


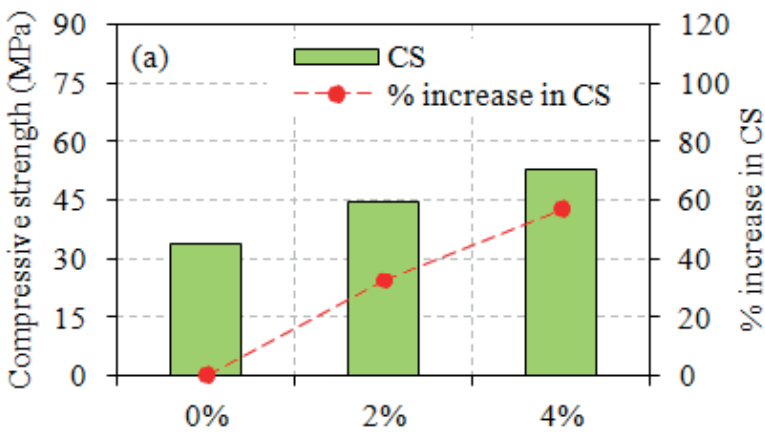

Fibre dosage (\%)
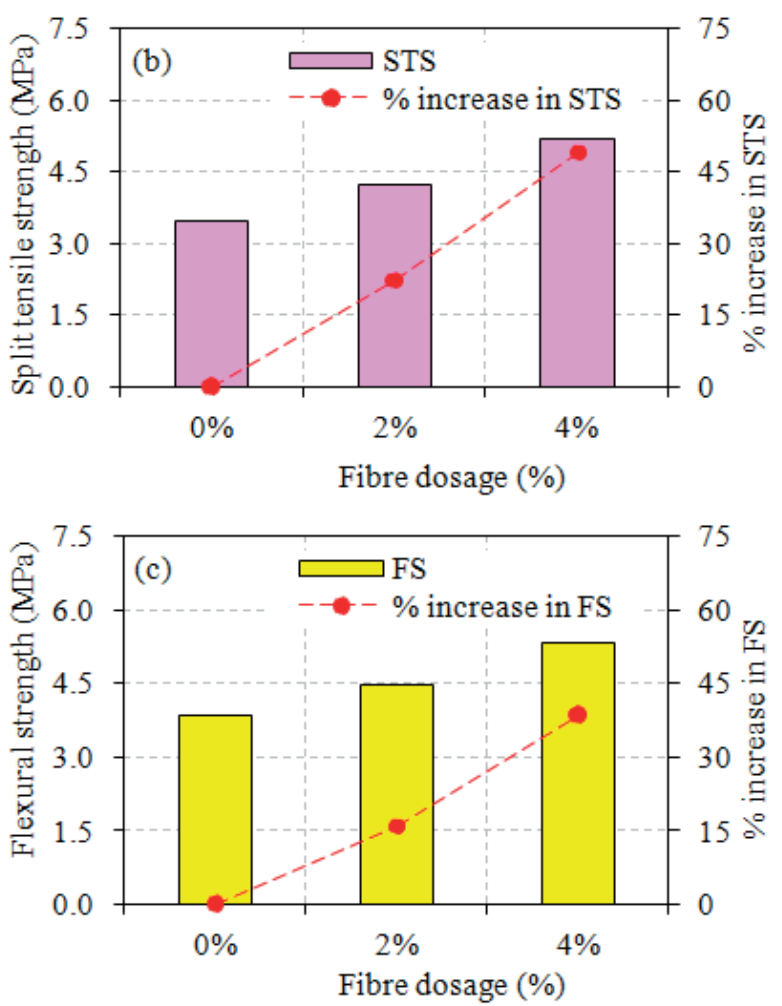

Fig. 11 Mechanical properties of PAFC

of PAFC had a rising trend as the dosage of fiber increased from 2 to $4 \%$. In the light of results in Fig. 11(a), the PAFC specimens made with 2 and $4 \%$ dosage of steel fibers achieved higher compressive strength around 32.9 and $56.9 \%$, respectively, as compared to the non-fibrous specimen. Generally, the dosage of steel fiber is traditional fibrous concrete is restricted to $2 \%$ as a result of workability issues and maintains a uniform fiber dispersion [16]. Henceforth, the higher dosage of steel fiber (i.e. exceeds $2 \%$ ) causes balling of fibers and grouping, forming voids and triggering weak spots and defects during crack initiation at the microscopic level, thus decreasing compressive strength [16]. Nehdi et al. [16] reported that exceptional compressive strength was achieved in this type of concrete by adding a higher dosage of steel fiber up to $6 \%$.
The reason for increased compressive strength due to the higher dosage of steel fibers and fiber bridging action which enhanced the resistance to crack development and proliferation, resulting in superior compressive strength [38].

The observed splitting tensile strength (STS) of PAFC specimens adding 2 and $4 \%$ dosage of steel fiber is illustrated in Fig. 11 (b). An intrinsic rise in splitting tensile strength was observed for the specimens containing 2 and $4 \%$ of steel fiber by about 22.5 and $49.3 \%$ respectively, compared with the non-fibrous specimen. Mostly, a trend of increasing tensile strength reported by many studies with increasing fiber content that are lined up along the tensile force [16]. Consequently, the orientation of the fibers within the concrete connection with tensile load dominates their tensile strength significantly. In traditional fibrous concrete, the orientation and distribution of fibers are impacted by the workability of concrete and placing the direction of concrete [39]. The dosage of steel fiber increasing more than $2 \%$ tends to display insufficient workability of traditional fibrous concrete, together with fiber balling effect and non-uniform fiber dispersion, resulting in a decrease of the tensile strength [40]. Contrarily, for the PAFC specimens containing a higher dosage of steel fibers (i.e. exceeds $2 \%$ ), fibers are dispersed randomly in the aggregate skeleton, which leads to many fibers passing across the failure plane. Henceforth, a higher dosage of steel fiber led to superior tensile strength [16]. This is ascribed to the function of steel fibers in crossing failure plane, hindering, and arresting the cracks [16].

Fig. 11(c) illustrates the results of the flexural strength (FS) of PAFC specimens composed of two different steel fiber dosages. Like traditional fibrous concrete, the fiber addition altered the mode of failure from brittle to ductile of the tested specimens. As anticipated, the addition of steel fibers in PAFC specimens significantly improved their flexural strength. For instance, the PAFC specimen comprising 2 and $4 \%$ of fiber dosage achieved 11 and $38.5 \%$ increase in flexural strength, respectively, as compared with the non-fibrous specimen. Normally, the flexural strength in traditional fibrous concrete had a significant impact on the fiber orientation, shape, length and dosage, and characteristics of the concrete matrix. The investigation established that the rise in flexural strength as the proper orientation of fibers in tensile flexural stresses direction [40]. In traditional fibrous concrete, the fiber distribution and orientation are influenced by the dosage of fibers, the workability of the matrix, and the casting direction of concrete [39]. Fiber addition excess of $2 \%$ can 
cause intermingle of fibers, resulting in their uneven dispersal [39]. This problem can overcome by improving the workability of fibrous concrete. Though, bleeding, aggregate and fiber segregation occur in high workable fibrous concrete, resulting decrease in flexural strength. On the contrary, during casting of fibrous concrete, a tendency of fibers aligned perpendicular direction to the flow of concrete, resulting in enhancement of flexural strength in one direction [39]. On the other hand, in PAFC specimens comprised of high fiber dosage, randomly distributed fibers were close to each other and spread more evenly. This allowing the flexural strength is greatly improved at a higher dosage of fiber which is inconceivable in traditional fibrous concrete.

\subsection{Load - deflection of TOHPB}

All beams were loaded slightly beyond the ultimate load. This phenomenon is due to the load beyond the ultimate load, the beams were suddenly broken into two pieces and fell over the LVDT, damaging LVDT during the test.

Fig. 12 illustrates the experimental test results of tested TOHPB. The diagram shows the sum of deflections on the $\mathrm{x}$-axis and corresponding load points on the $\mathrm{y}$-axis. According to the assumption made for the design, the TOHPB seems to perform elastic manner at the design load. It can be noticed prudently from Fig. 12, and the PC beam sustained lesser loads as a consequence of its lower tensile membrane action and structural stiffness. When the beam failed, the ultimate load and corresponding sum of deflections of the PC beam were $12 \mathrm{kN}$ and $0.021 \mathrm{~mm}$, respectively. At the same time, the NB-0TOHPB beam experienced an irrecoverable deflection of $0.061 \mathrm{~mm}$ with a corresponding load of $16 \mathrm{kN}$. Concerning the capacity

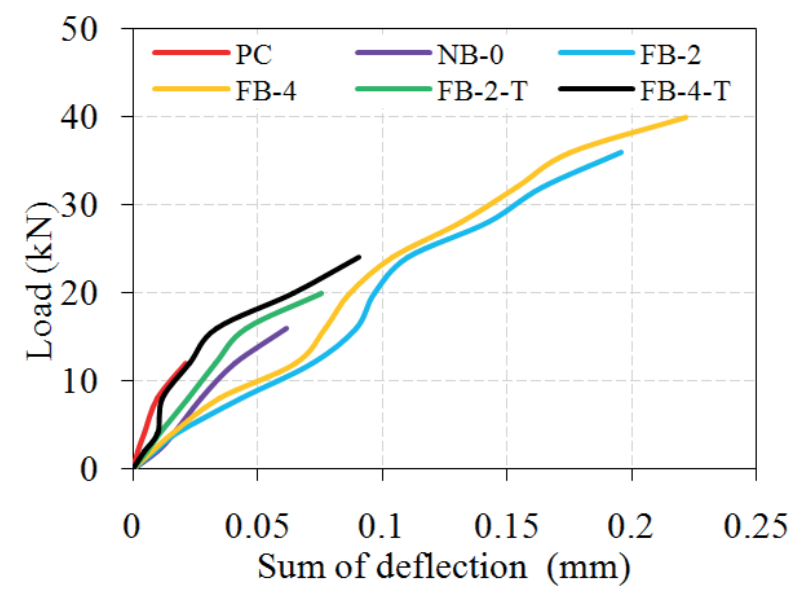

Fig. 12 Displacements for all tested TOHPB of the ultimate load, it was indicated that NB- 0 beam performed $33 \%$ better than the PC beam. Also, it is noticed to be both stronger and stiffer than the $\mathrm{PC}$ beam. Incorporation of fiber in TOHPB experienced to elastic phase, deflection hardening phase, and deflection softening phase. The elastic load is defined as the initial crack load of TOHPB in Fig. 12, which is unclear. The deflection hardening phase is reached progressively after the elastic phase (elastic load), demonstrating the ductility of fibrous TOHPB is good to compare to the NB- 0 and PC beam. Adding a $2 \%$ dosage of steel fibers only offers exceptional deflection hardening behavior compared to the NB-0 beam. The ultimate load and sum of deflections of the FB-2 beam were $36 \mathrm{kN}$ and $0.195 \mathrm{~mm}$, respectively, the load value was increased by about $125 \%$, compared to the NB-0 beam. Adding a $2 \%$ dosage of steel fiber in the TOHPB beam (FB-2) can lead to a significant deflection hardening behavior, and a $4 \%$ dosage of fibers improves further this behavior. For the FB-4 beam, the ultimate load and sum of deflections were $40 \mathrm{kN}$ and $0.221 \mathrm{~mm}$. The ultimate load value was increased by $150 \%$ compared to NB-0 and $11 \%$ compared to the FB-4 beam. The influence of better reinforcing is ascribed to high fiber content, good anchorage effect of crimpedhooked end fiber, effective stress transfer in cracked specimens, fiber bridging action in the cracked section, and postponing crack initiation and propagation.

Furthermore, by adding 2 and $4 \%$ dosage of steel fibers only in the failure zone of TOHPB beam (Top half of beam), the load-deflection curves of TOHPB beam can be decreased significantly for both peak load, as illustrated in Fig. 12. The observed ultimate load of FB-2-T and FB-4-T beams were $20 \mathrm{kN}$, and $24 \mathrm{kN}$, respectively, and the corresponding deflections were $0.075 \mathrm{~mm}$ and $0.090 \mathrm{~mm}$, respectively. By comparing with the NB-0 beam, the load values increased by about $67 \%$ in the case of FB-2-T and $100 \%$ in the FB-4-T beam. On the other hand, the ultimate load values for the FB-2-T beam was decreased by $80 \%$ in comparison to the FB-2 beam. Likewise, a $16 \%$ decrease in load value was observed in FB-4-T beam compared to the FB-4 beam. This may be attributed to the stress concentration occurs near the beam bottom, inefficient load transfer, non-fibrous concrete at bottom region resulted in decrease the load-bearing capacity. It is clear from the above discussions, and the TOHPB beam reinforced full cross-section exhibited better performance, which is recommended for designing the TOHPB beam in the application of bridge engineering. 


\subsection{Damage pattern of TOHPB under static load}

The PC and NB-0 beams are very brittle and breakdown into two components with a small load, as illustrated in Fig. 13. The fibrous the TOHPB showed superior bending stiffness and a similar failure pattern to that of non-fibrous beams. A smaller width of crack was exhibited in all fibrous TOHPB, and they appeared on the top chord of beam surface under fiber presence and moved to the lower portion of the top chord, as illustrated in Fig. 13. Despite the similar failure patterns observed in the non-fibrous and fibrous beam, the fibrous beam improves their residual bearing capacities to a greater extent. This observation emphasizes the ability of fibers capable of restraining crack growth, consequently delaying the beam from disintegrating into two components. This phenomenon is due to fiber bridging action, which can be altering the cracking pattern from brittle to ductile, in turn alleviating the damage imposed. Besides, the ductile failure mode extends the time frame for the evacuation of people, the primary aspect of disaster mitigation. The crack configuration noted in the current study is in proper alignment with earlier findings [31].

\section{Conclusions}

Topology optimized hammerhead pier beam is indeed suitable for bridges the summary of conclusions thus far drawn are as follows:

1. The emphasis of this line of research has been on the design of the concrete structure with better outcomes in the elastic range. The two used design outlines, first targeted at producing a rigid structural design with a specific quantity of material and second targeting to produce light in weight structure with constrained stress field. By comparing the experimental exploits of the diverse design outlines recommend that the target considered normally will have little awareness of the local concrete composites. Many performance properties cannot control the design and have been spotted to differ greatly between the tested beams in the same design case. Though, as most structural components have a multitude of performance supplies, there is an essentiality for adding a multitude of performance in the design preparation.

2. The highest compressive strength, split tensile strength and flexural strength were observed in specimen comprising $4 \%$ fiber dosage of steel fibers. Normally, the fiber dosage should not be more than $2 \%$ in conventional concrete to avoid the fiber balling effect, non-uniform distribution of fibers, and an increase in voids and workability issues that reduce mechanical properties. PAFC casting technique avoids this issue as a higher dosage of fibers, and coarse aggregates were packed into the mold before grout injection.

3. The TOHPB beam reinforced full cross-section (FB-2 and FB-4) exhibited a better ultimate load performance than that of the beam with half reinforced crosssection (FB-2-T and FB-4-T). This phenomenon is attributed to the effective stress concentration, fiber bridging action, and efficient load transfer increased the load-bearing capacity.

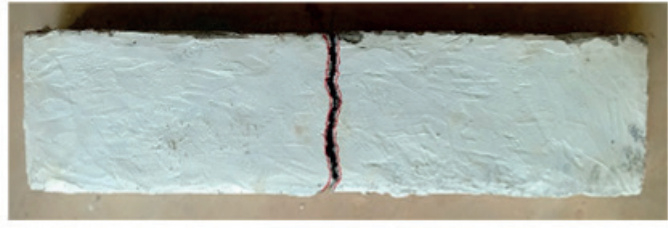

(a) $\mathrm{PC}$

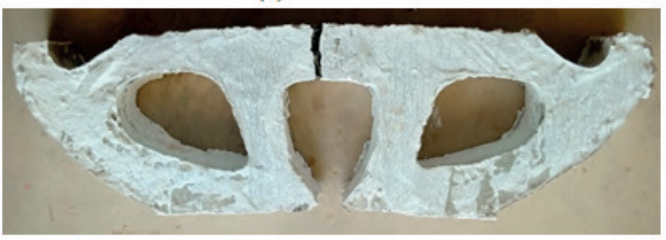

(c) FB-2

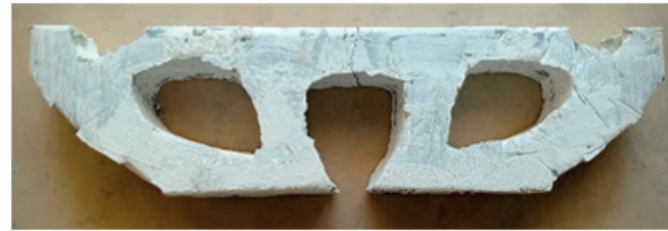

(e) FB-2-T

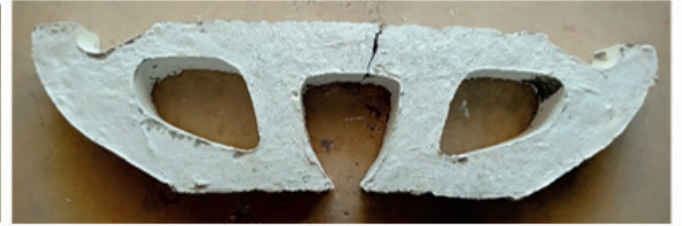

(b) NB0

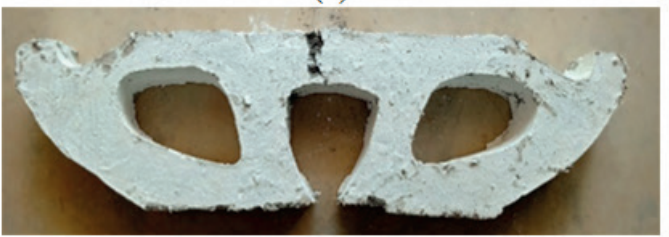

(d) FB-4

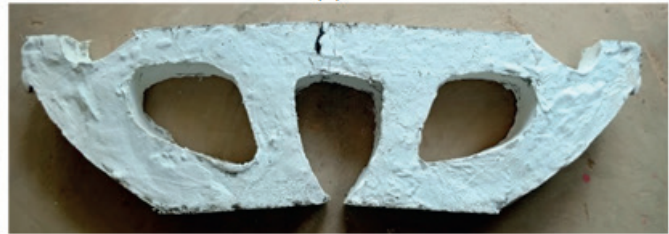

(f) FB-4-T

Fig 13 Typical damage pattern of all TOHPB under static load 
4. A similar failure pattern was observed in the non-fibrous and the fibrous beam. The fibrous beam improves their residual bearing capacities to a greater extent due to the fibers capable of restraining crack growth, delaying the beam from disintegrating into two components.

\section{References}

[1] Amir, O. "A topology optimization procedure for reinforced concrete structures", Computers and Structures, 114-115, pp. 46-58, 2013. https://doi.org/10.1016/j.compstruc.2012.10.011

[2] Sigmund, O., Bendsøe, M. P. "Topology optimization: from airplanes to nanooptics", In: Stubkjær, K., Kortenbach, T. (eds.) BRIDGING from technology to society: DTU 1829-2004 - 175 år, Technical University of Denmark, Lyngby, Denmark, 2004, pp. 40-51.

[3] Klee, H. "The cement sustainability initiative", Proceedings of the Institution of Civil Engineers, Engineering Sustainability, 157(ES2), pp. 9-12, 2004.

[4] Mahasenan, N., Smith, S., Humphreys, K. "The Cement Industry and Global Climate Change: Current and Potential Future Cement Industry $\mathrm{CO}_{2}$ Emissions", In: Proceedings of the 6th International Conference on Greenhouse Gas Control Technologies, Kyoto, Japan, Oct. 1-4, 2003, pp. 995-1000.

https://doi.org/10.1016/B978-008044276-1/50157-4

[5] Stromberg, L. L., Beghini, A., Baker, W. F., Paulino, G. H. "Application of layout and topology optimization using pattern gradation for the conceptual design of buildings", Structural and Multidisciplinary Optimization, 43, pp. 165-180, 2011.

https://doi.org/10.1007/s00158-010-0563-1

[6] Biondini, F., Bontempi, F., Malerba, P. G. "Optimal strut-andtie models in reinforced concrete structures", Computer Assisted Mechanics and Engineering Sciences, 6(3-4), pp. 280-293, 1999.

[7] Victoria, M., Querin, O. M., Martí, P. "Generation of strut-andtie models by topology design using different material properties in tension and compression", Structural and Multidisciplinary Optimization, 44(2), pp. 247-258, 2011.

https://doi.org/10.1007/s00158-011-0633-Z

[8] Yang, Y., Moen, C. D., Guest, J. K. "Three-Dimensional Force Flow Paths and Reinforcement Design in Concrete via Stress-Dependent Truss-Continuum Topology Optimization", Journal of Engineering Mechanics, 141(1), Article number: 04014106, 2015. https://doi.org/10.1061/(asce)em.1943-7889.0000819

[9] Bogomolny, M., Amir, O. "Conceptual design of reinforced concrete structures using topology optimization with elastoplastic material modeling", International Journal for Numerical Methods in Engineering, 90(13), pp. 1578-1597, 2012.

https://doi.org/10.1002/nme.4253

[10] Shaw, D., Miles, J., Gray, A. "Determining the structural layout of orthogonal framed buildings", Computers and Structures, 86(19-20), pp. 1856-1864, 2008.

https://doi.org/10.1016/j.compstruc.2008.04.009

[11] Briseghella, B., Fenu, L., Feng, Y., Mazzarolo, E., Zordan, T. "Topology Optimization of Bridges Supported by a Concrete Shell", Structural Engineering International, 23(3), pp. 285-294, 2013. https://doi.org/10.2749/101686613X13363929988214

\section{Acknowledgements}

The authors deeply grateful to the support provided by the School of Civil Engineering, SASTRA Deemed to be University.

[12] Kato, J., Ramm, E. "Optimization of fiber geometry for fibber reinforced composites considering damage", Finite Elements in Analysis and Design, 46(5), pp. 401-415, 2010.

https://doi.org/10.1016/j.finel.2010.01.001

[13] Oviedo, R., Gutiérrez, S., Santa María, H. "Experimental evaluation of optimized strut-and-tie models for a dapped beam", Structural Concrete, 17(3), pp. 469-480, 2016.

https://doi.org/10.1002/suco.201500037

[14] Amir, O., Shakour, E. "Simultaneous shape and topology optimization of prestressed concrete beams", Structural and Multidisciplinary Optimization, 57, pp. 1831-1843, 2018.

https://doi.org/10.1007/s00158-017-1855-5

[15] Søndergaard, A., Dombernowsky, P. "Design, Analysis And Realization Of Topology Optimized Concrete Structures", International Association for Shell and Spatial Structures, 53(4), pp. 209-216, 2012.

[16] Nehdi, M. L., Najjar, M. F., Soliman, A. M., Azabi, T. M. "Novel steel fibre-reinforced preplaced aggregate concrete with superior mechanical performance", Cement and Concrete Composites, 82, pp. 242-251, 2017.

https://doi.org/10.1016/j.cemconcomp.2017.07.002

[17] Najjar, M. F., Soliman, A. M., Nehdi, M. L. "Critical overview of two-stage concrete: Properties and applications", Construction and Building Materials, 62, pp. 47-58, 2014.

https://doi.org/10.1016/j.conbuildmat.2014.03.021

[18] Lambe, A. B., Czekanski, A. "Topology optimization using a continuous density field and adaptive mesh refinement", International Journal for Numerical Methods in Engineering, 113(3), pp. 357373, 2017.

https://doi.org/10.1002/nme.5617

[19] Bendsøe, M. P., Kikuchi, N. "Generating Optimal Topologies in Structural Design Using a Homogenization Method", Computer Methods in Applied Mechanics and Engineering, 71(2), pp. 197-224, 1988. https://doi.org/10.1016/0045-7825(88)90086-2

[20] Guest, J. K., Prévost, J. H., Belytschko, T. "Achieving minimum length scale in topology optimization using nodal design variables and projection functions", International Journal for Numerical Methods in Engineering, 61(2), pp. 238-254, 2004.

https://doi.org/10.1002/nme.1064

[21] Lógó, J. "New Type of Optimality Criteria Method in Case of Probabilistic Loading Conditions", Mechanics Based Design of Structures and Machines, 35(2), pp. 147-162, 2007. https://doi.org/10.1080/15397730701243066

[22] Lógó, J., Ghaemi, M., Rad, M. M. "Optimal Topologies in Case of Probabilistic Loading: The Influence of Load Correlation", Mechanics Based Design of Structures and Machines, 37(3), pp. 327-348, 2009.

https://doi.org/10.1080/15397730902936328 
[23] Lógó, J., Ghaemi, M., Vásárhelyi, A., Rad, M. M. "Topology Optimization in Case of Uncertain Load Positions", In: Proceedings of the 8th ASMO UK Conference on Engineering Design Optimization, London, UK, 2010, pp. 247-257. [online] Available at: http://www.asmo-uk.com/8th-asmo-uk/html/menu_page.html

[24] Lógó, J., Movahedi Rad, M., Tamássy, T., Knabel, J., Tauzowski, P. "Reliability based optimal design of frames with limited residual strain energy capacity", In: Proceedings of the Twelfth International Conference on Civil, Structural and Environmental Engineering Computing, Madeira, Portugal, 2009, pp. 13-20.

https://doi.org/10.4203/ccp.91.52

[25] Lógó, J., Movahedi Rad, M., Knabel, J., Tauzowski, P. "Reliability based design of frames with limited residual strain energy capacity", Periodica Polytechnica Civil Engineering, 55(1), pp. 13-20, 2011. https://doi.org/10.3311/pp.ci.2011-1.02

[26] Lógó, J., Vásárhelyi, A., Rad, M. M., Stocki, R. "Reliability based limit analysis of steel frames with limited residual strain energy capacity", Proceedings in Applied Mathematics and Mechanics, 8(1), pp. 10041-10044, 2008. https://doi.org/10.1002/pamm.200810041

[27] Svanberg, K. "The method of moving asymptotes - a new method for structural optimization", International Journal for Numerical Methods in Engineering, 24(2), pp. 359-373, 1987. https://doi.org/10.1002/nme.1620240207

[28] Rodrigues, H. C., Fernandes, P. A. "Topology Optimization of Linear Elastic Structures Subjected to Thermal Loads", In: Bendsøe, M. P., Soares, C. A. M. (eds.) Topology Design of Structures. NATO ASI Series (Series E: Applied Sciences), 227. Springer, Dordrecht, The Netherlands, 1993. https://doi.org/10.1007/978-94-011-1804-0_31

[29] Seo, Y.-D., Kim, H.-J., Youn, S.-K. "Shape optimization and its extension to topological design based on isogeometric analysis", International Journal of Solids and Structures, 47(11-12), pp. 1618$1640,2010$.

https://doi.org/10.1016/j.ijsolstr.2010.03.004

[30] Salaimanimagudam, M. P., Suribabu, C. R., Murali, G., Abid, S. R. "Impact Response of Hammerhead Pier Fibrous Concrete Beams Designed with Topology Optimization", Periodica Polytechnica Civil Engineering, 2020.

https://doi.org/10.3311/PPci.16664
[31] Jewett, J. L., Carstensen, J. V. "Topology-optimized design, construction and experimental evaluation of concrete beams", Automation in Construction, 102, pp. 59-67, 2019. https://doi.org/10.1016/j.autcon.2019.02.001

[32] IS "IS 1489-1 Specification for Portland Pozzolana Cement", Bureau of Indian Standards, New Delhi, India, 1991.

[33] IS "IS 383-2016 Coarse and Fine Aggregate for Concrete Specification (Third Revision)", Bureau of Indian Standards, New Delhi, India, 2016.

[34] ASTM "ASTM C939 - 10 Standard Test Method for Flow of Grout for Preplaced-Aggregate Concrete (Flow Cone Method)", West Conshohocken, PA, USA, 2010. https://doi.org/10.1520/C0939-10

[35] ACI "ACI 304.1R Guide for the Use of Preplaced Aggregate Concrete for Structural and Mass Concrete Applications pdf Download", American Concrete Institute, Farmington Hills, MI, USA, 19922005.

[36] IS "IS 516-1959 Method of Tests for Strength of Concrete", Bureau of Indian Standards, New Delhi, India, 1991.

[37] IS "IS 5816:1999 Splitting Tensile Strength of Concrete - Method of Test (First Revision)", Bureau of Indian Standards, New Delhi, India, 1999.

[38] Farnam, Y., Moosavi, M., Shekarchi, M., Babanajad, S. K., Bagherzadeh, A. "Behaviour of Slurry Infiltrated Fibre Concrete (SIFCON) Under Triaxial Compression", Cement and Concrete Research, 40(11), pp. 1571-1581, 2010.

[39] Zofka, A., Paliukaite, M., Vaitkus, A., Maliszewska, D., Josen, R., Bernier, A. "Laboratory Study on the Influence of Casting on Properties of Ultra-High Performance Fibre Reinforced Concrete (UHPFRC) Specimens", Journal of Civil Engineering and management, 20(3), pp. 380-388, 2014.

https://doi.org/10.3846/13923730.2014.913680

[40] Boulekbache, B., Hamrat, M., Chemrouk, M., Amziane, S. "Flowability of fibre-reinforced concrete and its effect on the mechanical properties of the material", Construction and Building Materials, 24(9), pp. 1664-1671, 2010. https://doi.org/10.1016/j.conbuildmat.2010.02.025 